\title{
Analisis Komparatif Kelayakan Investasi Antara Kendaraan Toyota Avanza Milik Sendiri Dengan Sewa di PT Pindad International Logistics Rute Bandung-Jakarta
}

\author{
Achmad Andriyanto., ST., MT. ${ }^{\text {) }}$, Nadlila Nuraisiyah ${ }^{2)}$ \\ ${ }_{1}$ D3 Logistik Bisnis, Politeknik Pos Indonesia \\ email: achmadandriyanto@poltekpos.ac.id \\ ${ }_{2}$ D3 Logistik Bisnis, Politeknik Pos Indonesia \\ email: nadlilanur14@gmail.com
}

\begin{abstract}
Abstrak
PT Pindad International Logistic merupakan sebuah perusahaan logistik terpadu yang menyediakan layanan jasa transportasi passanger. Kendaraan Toyota Avanza untuk rute Bandung-Jakarta yang digunakan oleh PT Pindad International Logistic dalam memenuhi bisnis jasa transportasi passanger merupakan kendaraan sewa dari vendor. Sehingga perusahaan berniat untuk mengetahui kelayakan investasi kendaraan Toyota Avanza untuk rute Bandung-Jakarta. Untuk membantu perusahaan mengetahui kelayakan investasi yang akan dilakukan, penulis mengusulkan agar perusahaan menggunakan Biaya Operasional Kendaraan (BOK), Net Present Value (NPV), dan Payback Period. Hasil penelitian untuk kendaraan jenis Toyota Avanza rute Bandung - Jakarta memiiki biaya sewa kepada vendor sebesar Rp. 534.250,./hari dan biaya operasional kendaraan milik sendiri sebesar Rp. 453.991,./hari. Nilai NPV sebesar Rp. 223.557.562,. (NPV>0) bernilai positif dan Payback Period selama 3 tahun 9 bulan. Maka, biaya yang dipilih perusahaan tetap menggunakan biaya operasional kendaraan milik sendiri dan melakukan investasi kendaraan milik sendiri.
\end{abstract}

Kata Kunci: Transportasi, Passanger, Kelayakan Investasi.

\section{PENDAHULUAN}

PT. Pindad International Logistic (PIL) adalah perusahaan jasa logistik terpadu yang menyediakan berbagai layanan logistic. Bisnis transportasi yang disediakan oleh PT. Pindad International Logistic terbagi menjadi 2 jenis, yaitu bisnis jasa transportasi angkutan barang dan bisnis jasa transportasi angkutan passanger (orang). Bisnis jasa angkutan passanger merupakan suatu bisnis transportasi kendaraan dinas yang disediakan oleh PT. Pindad International Logistic untuk melayani kegiatan dinas dari seluruh karyawan yang ada di PT. Pindad (Persero). Dalam menjalankan kegiatan bisnisnya dibidang jasa transportasi passanger, menggunakan kendaraan jenis Toyota Avanza dan Toyota Kijang Innova untuk dapat melayani kegiatan dinas dari seluruh permintaan karyawan PT. Pindad (Persero). Permasalahan yang sering terjadi yaitu jumlah kendaraan yang digunakan oleh PT. Pindad International Logistic tidak mencukupi untuk dapat menunjang permintaan kendaraan dinas dari karyawan PT. Pindad (Persero). Hal ini terjadi karena kendaraan yang digunakan oleh perusahaan menggunakan kendaraan sewa yang memiliki keterbatasan jumlah. PT. Pindad International Logistic berencana untuk melakukan investasi kendaraan Toyota Avanza milik sendiri secara bertahap untuk menunjang bisnis jasa transportasi passanger khususnya untuk rute BandungJakarta karena permintaannya cukup tinggi.

Terdapat beberapa penelitian terdahulu mengenai kelayakan investasi kendaraan. Penelitian oleh Kadek Rekhi (2015) memiliki tujuan untuk analisis kelayakan kendaraan milik pribadi menggunakan Biaya Operasional Kendaraan (BOK) dibandingkan dengan biaya menyewa kendaraan, dan didukung dengan perhitungan analisa kelayakan investasi kendaraan. Penelitian oleh Theresia (2015) bertujuan untuk mengetahui kelayakan melakukan investasi dump truck dengan tingkat suku bunga bank menggunakan metode Net Present Value (NPV). Penelitian lain dilakukan oleh Cok Putra Wirasutama, dkk (2015) untuk menganalisis kelayakan angkutan pariwisata 
secara finansial dengan menggunakan metode Net Present Value (NPV) dan Payback Period.

Berdasarkan permasalahan yang terjadi, peneliti menerapkan metode Biaya Operasional Kendaraan (BOK), Net Present Value (NPV) dan Payback Period. Biaya Operasional Kendaraan (BOK) digunakan untuk menganalisis tingkat efisiensi antara membeli kendaraan dengan menyewa kedaraan dari vendor lain, Net Present Value (NPV) digunakan untuk menganalisis uji kelayakan investasi kendaraan yang akan dilakukan oleh sebuah perusahaan, Payback Period digunakan untuk menganalisis jangka waktu pengembalian atas modal Investasi yang dikeluarkan oleh perusahaan. Tujuan dulakukannya penelitian ini untuk mengetahui kelayakan investasi yang akan dilakukan oleh PT Pindad International Logistic.

\section{METODE PENELITIAN}

Metode yang digunakan untuk memecahkan permasalahan ini yaitu metode Biaya Operasional Kendaraan (BOK), Net Present Value (NPV), dan Payback Period dengan tahapan sebagai berikut:

a. Menghitung biaya sewa kendaraan dari vendor

Pada tahap ini perhitungan dilakukan berdasarkan biaya tetap, biaya tidak tetap, dan biaya overhead kendaraan sewa kepada vendor.

b. Menghitung biaya tetap

Biaya tetap dihitung berdasarkan penjumlahan komponen biaya tetap seperti biaya penyusutan kendaraan, biaya pajak kendaraan dan biaya gaji awak kendaraan

Biaya tetap = biaya penyusutan kendaraan + biaya pajak kendaraan + biaya gaji awak

c. Menghitung biaya tidak tetap

Biaya tidak tetap dihitung berdasarkan penjumlahan komponen biaya tidak tetap seperti biaya service, biaya BBM, dan biaya penggunaan ban.

Biaya tidak tetap $=$ biaya service + biaya

$$
B B M+\text { biaya penggunaan ban }
$$

d. Menghitung biaya overhead

Biaya overhead dihitung berdasarkan penjumlahan komponen biaya overhead seperti biaya tol.
Biaya tidak tetap = biaya tol

e. Menghitung biaya operasional kendaraan

Biaya operasional kendaraan dihitung berdasarkan penjumlahan biaya tetap, biaya tidaktetap, dan biaya overhead.

Biaya operasional kendaraan = biaya tetap

+ biaya tidak tetap + biaya overhead

f. Menghitung kelayakan investasi kendaraan

Kelayakan investasi kendaraan dihitung menggunakan bantuan metode Net Present Value (NPV) dan Payback Period.

$N P V=$ Total P.Income - Total P.Cost

$P B P=\frac{\text { nilai investasi }}{\text { pendapatan } / \text { tahun }} \times$ tahun

g. Keputusan sewa atau beli kendaraan

Tahap ini dilakukan berdasarkan perbandingan hasil perhitungan biaya operasional kendaraan sewa dan milik sendiri serta kelayakan investasi.

\section{HASIL DAN PEMBAHASAN}

a. Perhitungan biaya sewa kendaraan dari vendor

- Harga sewa kendaraan Toyota Avanza Rp. 5.550.000/bulan.

- Gaji Driver Rp. 1.200.000.000/bulan

\begin{tabular}{|l|r|}
\hline \multicolumn{1}{|c|}{ JENIS BIAYA } & \multicolumn{1}{c|}{$\begin{array}{c}\text { JUMLAH } \\
\text { BIAYA (Rp) }\end{array}$} \\
\hline $\begin{array}{l}\text { Biaya sewa dari } \\
\text { vendor/tahun }\end{array}$ & $66.600 .000,$. \\
\hline $\begin{array}{l}\text { Gaji awak kendaraan } \\
\text { pertahun }\end{array}$ & $14.400 .000,$. \\
\hline $\begin{array}{l}\text { Biaya tetap = Biaya sewa dari vendor }+ \\
\text { Gaji awak kendaraan/tahun }\end{array}$ \\
\hline Biaya tetap/tahun & $81.000 .000,$. \\
\hline Biaya tetap/bulan & $6.750 .000,$. \\
\hline Biaya tetap/hari & $281.250,$. \\
\hline
\end{tabular}

- Harga bensin Rp. 7.650,./liter

- Jarak tempuh $302 \mathrm{~km} / \mathrm{hari}$

- Rasio bensin 15 km/liter

\begin{tabular}{|c|c|}
\hline JENIS BIAYA & JUMLAH \\
& BIAYA (Rp) \\
\hline
\end{tabular}




\begin{tabular}{|l|r|}
\hline Biaya bahan bakar/tahun & $44.064 .000,$. \\
\hline $\begin{array}{l}\text { Biaya tidak tetap }= \\
\text { bakar/tahun }\end{array}$ \\
\hline Biaya tidak tetap/tahun & $44.064 .000,$. \\
\hline Biaya tidak tetap/bulan & $3.670 .500,$. \\
\hline Biaya tidak tetap/hari & $152.978,$. \\
\hline
\end{tabular}

- Biaya tol Rp. 100.000,./rit

\begin{tabular}{|l|r|}
\hline \multicolumn{1}{|c|}{ JENIS BIAYA } & $\begin{array}{c}\text { JUMLAH } \\
\text { BIAYA (Rp) }\end{array}$ \\
\hline Biaya tol/tahun & $28.800 .000,$. \\
\hline Biaya overhead = biaya tol \\
\hline Biaya overhead/tahun & $28.800 .000,$. \\
\hline Biaya overhead/bulan & $2.400 .000,$. \\
\hline Biaya overhead/hari & $100.000,$. \\
\hline
\end{tabular}

- Akumulasi biaya operasional kedaraan sewa

\begin{tabular}{|c|c|}
\hline JENIS BIAYA & $\begin{array}{c}\text { JUMLAH } \\
\text { BIAYA (Rp) }\end{array}$ \\
\hline Biaya tetap/tahun & 81.000.000, \\
\hline Biaya tidak tetap/tahun & 44.064.000,. \\
\hline Biaya overhead/tahun & 28.800.000,. \\
\hline \multicolumn{2}{|c|}{$\begin{array}{l}\text { Biaya Operasional Kendaraan }=\text { Biaya } \\
\text { tetap/tahun }+ \text { Biaya tidak tetap/tahun }+ \\
\text { Biaya overhead/tahun }\end{array}$} \\
\hline $\begin{array}{l}\text { Biaya operasional } \\
\text { kendaraan }(\mathrm{BOK}) / \text { tahun }\end{array}$ & 153.864.000,. \\
\hline $\begin{array}{l}\text { Biaya operasional } \\
\text { kendaraan }(\mathrm{BOK}) / \text { bulan }\end{array}$ & 12.822.000, \\
\hline $\begin{array}{l}\text { Biaya operasional } \\
\text { kendaraan }(\mathrm{BOK}) / \text { hari }\end{array}$ & 534.250, \\
\hline
\end{tabular}

b. Perhitungan biaya tetap

- Umur ekonomis kendaraan 5 tahun

- Harga kendaraan baru Rp. 230.000.000

- Biaya penyusutan/tahun:

$\mathrm{D}=\mathrm{P} / \mathrm{n}=230.000 .000 / 5$

$=$ Rp. 46.000.000/tahun

- Gaji driver Rp. 1.200.000,./bulan

\section{JENIS BIAYA}

JUMLAH

\begin{tabular}{|l|r|}
\hline & BIAYA (Rp) \\
\hline Biaya penyusutan/tahun & $46.000 .000,$. \\
\hline $\begin{array}{l}\text { Perijinan dan } \\
\text { administrasi/tahun }\end{array}$ & $2.800 .000,$. \\
\hline $\begin{array}{l}\text { Gaji awak kendaraan } \\
\text { pertahun }\end{array}$ & $14.400 .000,$. \\
\hline
\end{tabular}

Biaya tetap $=$ Biaya penyusutan $/$ tahun +

Perijinan dan administrasi/tahun + Gaji awak kendaraan/tahun

\begin{tabular}{|l|r|}
\hline Biaya tetap/tahun & $63.200 .000,$. \\
\hline Biaya tetap/bulan & $5.266 .667,$. \\
\hline Biaya tetap/hari & $202.564,$. \\
\hline
\end{tabular}

c. Perhitungan biaya tidak tetap

- Servis ringan

\begin{tabular}{|l|r|}
\hline KOMPONEN SERVIS & BIAYA (Rp) \\
\hline Ganti oli & $350.000,$. \\
\hline Minyak rem & $25.000,$. \\
\hline Upah servis & $50.000,$. \\
\hline TOTAL BIAYA & $\mathbf{4 2 5 . 0 0 0 , .}$ \\
\hline
\end{tabular}

Jangka waktu servis $10.000 \mathrm{~km}$

Jarak tempuh $86.976 \mathrm{~km} /$ tahun

Jumlah servis

$$
\begin{aligned}
& =\frac{\text { jarak tempuh } / \text { tahun }}{\text { jangka waktu servis ringan }} \\
& =\frac{86.976 \mathrm{~km} / \text { tahun }}{10.000 \mathrm{~km}}=8,69 \\
& =9 \mathrm{kali} / \text { tahun }
\end{aligned}
$$

Biaya servis $=9 \times$ Rp. 425.000,.

$=$ Rp. 3.825.000,./tahun

- Service berat

\begin{tabular}{|l|r|}
\hline KOMPONEN SERVIS & BIAYA (Rp) \\
\hline Oli Mesin & $350.000,$. \\
\hline Filter Oli & $30.000,$. \\
\hline Gasket & $9.000,$. \\
\hline Saringan Udara & $90.000,$. \\
\hline Oli Gardan & $120.000,$. \\
\hline Oli Transmisi & $110.000,$. \\
\hline Minyak rem & $25.000,$. \\
\hline Upah servis & $100.000,$. \\
\hline
\end{tabular}


Jangka waktu servis $50.000 \mathrm{~km}$

Jarak tempuh $86.976 \mathrm{~km} /$ tahun

$$
\begin{aligned}
\text { Jumlah servis } & =\frac{86.976 \mathrm{~km} / \text { tahun }}{50.000 \mathrm{~km}} \\
& =1,74 \mathrm{kali} / \text { tahun }
\end{aligned}
$$

Perusahaan menetapkan servis berat hanya dilakukan 1 kali/tahun

Biaya servis

$=$ Jumlah servis $\mathrm{x}$ total biaya servis

$=1 \times$ Rp. 834.000,

$=$ Rp. 834.000,./tahun

- BBM

Harga bensin Rp. 7.650,./liter

Jarak tempuh $302 \mathrm{~km} /$ hari

Rasio bensin 15 km/liter

Pemakaian bensin/hari

$=302 / 15$

$=20$ liter/hari

Biaya bensin/hari

$=20 \times$ Rp. 7.650,

$=$ Rp. 153.000,./hari

Biaya bensin

$=$ Rp. 3.672.000, x 12

$=$ Rp. 44.064.000,./tahun

- Penggunaan ban

Harga ban baru Rp. 530.000,

Daya tahan ban $50.000 \mathrm{~km}$

Jumlah ban 4 ban

Jumlah $\mathrm{km} /$ tahun $=86.976 \mathrm{~km} /$ tahun

Biaya pemakaian ban/tahun

$=\frac{\text { harga ban } \times \mathrm{km} / \text { tahun }}{\text { daya tahan ban }}$

= Rp.530.000 $\times 86.976 \mathrm{~km}$

$50.000 \mathrm{~km}$

$=$ Rp. 921.946,./tahun

- Akumulasi Biaya Tidak Tetap

\begin{tabular}{|l|r|}
\hline \multicolumn{1}{|c|}{ JENIS BIAYA } & \multicolumn{1}{c|}{$\begin{array}{c}\text { JUMLAH } \\
\text { BIAYA (Rp) }\end{array}$} \\
\hline Biaya servis ringan/tahun & $3.825 .000,$. \\
\hline Biaya servis berat/tahun & $834.000,$. \\
\hline Biaya bahan bakar/tahun & $44.064 .000,$. \\
\hline $\begin{array}{l}\text { Biaya pemakaian } \\
\text { ban/tahun }\end{array}$ \\
\hline \begin{tabular}{l} 
Biaya tidak tetap = Biaya service \\
ringan/tahun + \\
berat/tahun + Biaya bahan bakar/tahun \\
+ Biaya pemakaian ban/tahun \\
\hline Biaya tidak tetap/tahun
\end{tabular} \\
\hline Biaya tidak tetap/bulan & $49.644 .946,$. \\
\hline Biaya tidak tetap/hari & $4.137 .079,$. \\
\hline
\end{tabular}

d. Perhitungan biaya overhead

- Biaya tol/rit = Rp. 100.000,./rit

- Akumulasi Biaya Overhead

\begin{tabular}{|l|r|}
\hline \multicolumn{1}{|c|}{ JENIS BIAYA } & $\begin{array}{c}\text { JUMLAH } \\
\text { BIAYA (Rp) }\end{array}$ \\
\hline Biaya tol/tahun & $28.800 .000,$. \\
\hline Biaya overhead = biaya tol \\
\hline Biaya overhead/tahun & $28.800 .000,$. \\
\hline Biaya overhead/bulan & $2.400 .000,$. \\
\hline Biaya overhead/hari & $100.000,$. \\
\hline
\end{tabular}

e. Perhitungan biaya operasional kendaraan

- Biaya tetap/tahun

= Rp. 63.200.000,./tahun

- Biaya tidak tetap/tahun

= Rp. 49.644.946,./ tahun

- Biaya overhead/tahun $=$ Rp. 28.800.000,./tahun

- Akumulasi BOK $=63.200 .000+49.644 .946+28.800 .000$

$=$ Rp. 141.644.946,./tahun

\begin{tabular}{|l|r|}
\hline \multicolumn{1}{|c|}{ JENIS BIAYA } & $\begin{array}{c}\text { JUMLAH } \\
\text { BIAYA (Rp) }\end{array}$ \\
\hline Biaya tetap/tahun & $63.200 .000,$. \\
\hline Biaya tidak tetap/tahun & $49.644 .946,$. \\
\hline Biaya overhead/tahun & $28.800 .000,$. \\
\hline Biaya Operasional Kendaraan = Biaya \\
\hline
\end{tabular}




\begin{tabular}{|c|c|}
\hline \multicolumn{2}{|c|}{$\begin{array}{l}\text { tetap/tahun }+ \text { Biaya tidak tetap/tahun }+ \\
\text { Biaya overhead/tahun }\end{array}$} \\
\hline $\begin{array}{l}\text { Biaya operasional } \\
\text { kendaraan }(\mathrm{BOK}) / \text { tahun }\end{array}$ & 141.644.946, \\
\hline $\begin{array}{l}\text { Biaya operasional } \\
\text { kendaraan }(\mathrm{BOK}) / \text { bulan }\end{array}$ & 11.803.746,. \\
\hline $\begin{array}{l}\text { Biaya operasional } \\
\text { kendaraan }(\mathrm{BOK}) / \text { hari }\end{array}$ & $991,$. \\
\hline
\end{tabular}

f. Perhitungan kelayakan investasi

Tarif kendaraan passanger Rp. 350.000

Pendapatan/tahun

$=$ Rp. $350.000 \times 288 \times 2$

$=$ Rp. 201.600.000,./tahun

- Net Present Value (NPV)

Total P. Income = Rp. 760.675.200,

Total P. Cost $=$ Rp. 537,117,638, .

$\mathrm{NPV}=$ Total P. Income - Total P. Cost

$=$ Rp. 760.675.200 - Rp. 537.117.638

$=$ Rp. 223.557.562,.

- Payback Period

Nilai investasi $=$ Rp. 230.000.000,

Pendapatan kotor

$=$ Rp. 201.600.000,./tahun

BOK = Rp. 141.644.946,./tahun

Pendapatan bersih :

$=$ Rp. 201.600.000-BOK

$=$ Rp. $201.600 .000-$ Rp. 141.644 .946

$=$ Rp. 59.955.054,./tahun

Payback period

$=\frac{\text { nilai investasi }}{\frac{\text { pendapatan }}{\text { tahun }}} \times$ tahun

$=\frac{R p \cdot 230.000 .000}{R p .59 .955 .054}$

$\times$ tahun $=3,84$ tahun

$=3$ tahun 9 bulan

\section{KESIMPULAN}

a. BOK milik sendiri:

- Rp. 141.644.946,./tahun

- Rp. 11.803.746,./bulan

- Rp. 453.991,./hari

BOK sewa :

- Rp. 153.864.000/tahun

- Rp. 12.822.000/bulan

- Rp. 534.250/hari.

b. Perbandingan BOK milik sendiri lebih murah dibandingkan dengan sewa.

c. Net Present Value (NPV) sebesar Rp. 59.955.054 dan Payback Period selama 3 tahun 9 bulan sehingga LAYAK untuk dilakukan investasi kendaraan secara finansial.

\section{REFERENSI}

\section{Jurnal:}

[1] Akbardin, Juang., Andri Eka Putra. 2016. Analisa Biaya Operasi Kendaraan (BOK) Shuttle Service Rute Bandung-Jakarta. Jurnal Teknik Sipil. Vol.14, No.01.

[2] Barbara, Theresia Ocnalica. 2015. Analisis Komparatif Antara Membeli Dan Menyewa Dump Truck PT. Global Daya Manunggal Di Sangatta. Administrasi Bisnis. Vol 3 (2): 336-350.

[3] Frans, John H., dkk. 2016. Kajian Tarif Angkutan Umum Berdasarkan Biaya Operasional Kendaraan (BOK), Ability To Pay (ATP) dan Willingness To Pay (WTP) di Kabupaten TTS. Jurnal Teknik Sipil. Vol.05, No.02.

[4] Mulyati, Erna., Aghitsna Iqbal Alif. 2014. Perencanaan Tarif Ideal Pengiriman Barang Berdasarkan Metode Perhitungan Biaya Operasional Kendaraan (BOK). Jurnal Ilmiah Teknik Industri. Vol. 12, No. 2.

[5] Nugroho, Handy., Ratna Purwaningsih. 2015. Analisis Tarif Berdasarkan Biaya Operasional Kendaraan (BOK) dan Willingness To Pay (WTP) pada Bus AKAP Kelas Executive. Jurnal Teknik Industri. Vol.10, No.10.

[6] Putra, Bagus Nugroho., Utami Sylvia Lestari. 2018. Analisis Biaya Operasional Kendaraan dan WTP (Willingness to Pay) pada Bus AKAP Jurusan BanjarmasinSamarinda. Jurnal Keilmuan Teknik Sipil. Vol. 01, No.02.

\section{Textbooks:}


[1] Putra, Bagus Nugroho., Utami Sylvia Lestari. 2018. Analisis Biaya Operasional Kendaraan dan WTP (Willingness to Pay) pada Bus AKAP Jurusan BanjarmasinSamarinda. Jurnal Keilmuan Teknik Sipil. Vol. 01, No.02.

[2] Gunawan, Herry. 2015. Pengantar Transportasi dan Logistik. Depok: PT. Rajagrafindo Persada.

[3] Miro, Fidel. 2012. Pengantar Sistem Transportasi. Jakarta: Erlangga.

[4] Nasution, M. Nur. 2004. Manajemen Transportasi. Bogor: Ghalia Indonesia

[5] Nasution, M. Nur. 2010. Manajemen Transportasi. Bogor: Ghalia Indonesia

[6] Rudianto. 2013. Akuntansi Manajemen. Jakarta: Erlangga.

[7] Rusdiana, A. 2014. Manajemen Operasi. Bandung: CV Pustaka Setia.

[8] Salim, Abbas. 2016. Manajemen Transportasi. Jakarta: PT. Ragagrafindo Persada.

[9] Siregar, Baldric. dkk. 2013. Akuntansi Manajemen. Jakarta: Salemba Empat

[10] Usman, Husnaini. 2016. Manajemen Teori, Praktik, dan Riset Pendidikan. Jakarta: PT. Bumi Aksara. 